\title{
Can Open Hand Injuries Wait for Their Surgery in a Tertiary Hospital?
}

\author{
Wei Ping Sim ${ }^{1}$ Hannah Jia Hui Ng ${ }^{1}$, Benjamin Zhiren Liang ${ }^{1} \quad$ Vaikunthan Rajaratnam ${ }^{1}$ \\ ${ }^{1}$ Hand and Reconstructive Microsurgery Service, Department \\ of Orthopaedic Surgery, Khoo Teck Puat Hospital, Singapore, \\ Singapore \\ Address for correspondence Hannah Jia Hui Ng, MBBS, \\ MRCS, 90 Yishun Central Singapore 768828 \\ (e-mail: hannahnjh@gmail.com).
}

J Hand Microsurg 2021;13:157-163.

\begin{abstract}
Keywords

- open injuries

- hand injuries

- infection

- deep infection

- semi-emergent surgery

Objective Open hand injuries are routinely admitted and planned for surgery acutely, competing with other surgical emergencies. This retrospective study aims to evaluate if a delay in timing to surgery for open hand injuries led to an increased rate of infection.

Materials and Methods All patients who sustained open hand injuries and underwent semi-emergent day surgery from January 1, 2015 to December 31, 2016 were included. Outcome of postoperative infection was analyzed against demographic data, injury details, and delay from trauma to therapy.

Results There were 232 cases (91\% males) included, with $92.0 \%$ performed under local anesthesia. Deep seated postoperative infection was seen in $1.3 \%$, which was not significantly associated with delay to surgery.

Conclusion We had comparable infection rates as compared with published literature. Delayed timing of surgical treatment in open hand injuries was not associated with increased rates of deep-seated infection. Managing open hand injuries as semi-emergent surgeries may be acceptable given the low infection rates.
\end{abstract}

\section{Introduction}

Hand injuries are common injuries, accounting for 12 to $20 \%$ of patient visits to emergency department (ED) in the United States. ${ }^{1-5}$ Sustaining hand and wrist injuries is also the most expensive types of injury to have, ahead of lower limb fractures and hip fractures. ${ }^{2}$ Many have advocated for more research to be done in this field to improve care and reduce cost for these injuries. ${ }^{2-4}$

For any open injury, there is always the worry of infection. The risk of infection is associated with factors such as antibiotic use, injury severity, and delay in time to surgical debridement. ${ }^{6-12}$ Delayed treatment of open hand injuries may occur due to limitations of operating theater (OT) availability, bed allocation constraints, difficult access to a hand

published online March 4, 2021 surgery center, and other comorbidities requiring stabilization prior to surgery. ${ }^{13,14}$

There is a historical critical time period of 6 hours to surgical debridement for open fractures. ${ }^{15}$ This has been extrapolated to other open injuries including those in the hand. However, this critical time period is still hotly debated, and the optimal time frame has yet to be established. ${ }^{14,16,17}$

The current practice at our tertiary hospital is for patients with open hand injuries to be managed in a semi-emergent, ambulatory setting. They are discharged from the ED, returning as a semi-emergent case for surgery in the Day Surgery Operating Theater (DSOT) in the next available slot. This system was adopted as our hospital often faces bed allocation and OT availability constraints. This novel system has proven to reduce inpatient admissions, man-hour wastage in the ED
(C) 2021. Society of Indian Hand \& Microsurgeons. All rights reserved. Thieme Medical and Scientific Publishers Pvt. Ltd., A-12, 2nd Floor, Sector 2, Noida-201301 UP, India
DOI https://doi.org/ $10.1055 / \mathrm{s}-0041-1725220$ ISSN 0974-3227. 
while awaiting bed allocation, unnecessary inpatient stay while awaiting OT availability, and also improved DSOT utilization. Patients are able to wait for their surgery at home, avoiding the hassle of inpatient stay.

In our local setting, patients are routinely admitted from the ED and planned for surgery acutely in the emergency setting. The purpose of this study is to evaluate if a delay in timing to surgery for open hand injuries due to performing surgeries as a semi-emergent day surgery procedure, resulted in an increased rate of infection.

\section{Materials and Methods}

This is a retrospective cohort study involving all consecutive patients, sustaining open hand injuries who were seen first in the ED and subsequently underwent semi-emergent surgery in DSOT from January 1, 2015 to December 31, 2016 in our local tertiary hospital in Singapore. Ethical approval (DSRB 2018/01315) was obtained.

Patients were excluded if they had sustained closed hand injuries; open injuries in the upper extremity apart from the fingers and hand; polytrauma patients who required inpatient observation or who had sustained other concomitant injuries requiring inpatient management; bite injuries (including fight bite and animal bite injuries); existing acute or chronic infections; severe injuries that required immediate attention for possible replantation or critical revascularization; and heavily contaminated or mutilated injuries.

Patients with injuries to multiple digits were analyzed as a single individual. Cases with missing data were omitted from analysis.

Admission to DSOT and outpatient follow-up data were reviewed on electronic medical records. Data collected were age, gender, location of injury, nature of injury, presence of fracture, initial intervention, pre- and postoperatively antibiotic therapy, type of surgical intervention, and timing of surgical intervention. Outcome parameters were occurrence of infection requiring medical and/or surgical intervention, associated culture results, and reoperation.

The types of surgery performed were categorized as follows: soft tissue debridement, tendon repair, surgical fixation, terminalization, skin grafting, bony debridement, local flap, nerve repair, arthrodesis, and complex reconstructions. Complex reconstruction is defined as cases that require repair of two or more tissue components (tendons, nerves, local/regional flaps, or bony fixation-not including joint immobilization using K-wire for the purpose of protecting tendon repair). For cases which involved multiple categories of procedures, the most complex procedure based on our local national procedure code were considered.

Time to surgical intervention was defined as time from presentation in the ED to surgical debridement. The time to surgical intervention was due to OT availability for all cases.

Patients are reviewed postoperatively in the hand surgery clinics by a surgical registrar grade or above. Occurrence of deep infection was recorded if the documentation stated explicitly that the patients had an infection or if signs of erythema, tenderness, swelling, and clinical suspicion of infection during their postoperative follow-up.

\section{Workflow in the Emergency Department}

Patients presenting to the ED with open hand injuries, which may warrant surgical management, are referred to the on-call hand surgery registrar for thorough evaluation. The registrar triages patients' injuries and determines which patients are amenable for semi-emergent surgery, where these cases are listed in the semi-emergent surgery list, or whether patients require emergency management and require admission.

Patients with potential nerve injuries are considered for semi-emergent surgery, provided no critical revascularization procedures are required. After office hours, patients who require critical revascularization or possible replantation are referred to a separate nearby tertiary hospital, as this service is not provided at our center after office hours due to manpower constraints. Heavily contaminated or mutilated injuries are admitted for intravenous (IV) antibiotics and possibly more urgent surgical management.

After review, cases with injuries amenable for semiemergent surgery have their wounds irrigated with at least $500 \mathrm{~mL}$ of normal saline followed by a sterile dressing.

Antibiotics are administered as deemed necessary by the ED physician. The patients are discharged by the ED physician based on the following criteria:

- Review by the hand surgery registrar

- Definitive follow-up plans given

- Sterile wound dressing performed

- Stable hemodynamics and adequate pain control

On the following day, the semi-emergency list of patients is reviewed by the hand surgery team, and the surgery is arranged in the next available slot in our DSOT.

\section{Standardized Treatment Protocol in Operating Theater and Follow-Up}

Prior to surgical debridement, the affected extremity is cleansed with standardized cleansing solutions of povidone iodine. Surgical debridement is performed by the hand surgery registrar under supervision of the hand surgical consultant or the hand surgical consultant. Postoperatively, oral antibiotics are routinely given.

Patients are discharged on the same day after surgery in DSOT with a close follow-up plan in the outpatient clinic.

Postoperatively, all patients are reviewed in the clinic within 2 to 5 days.

Simple injuries without any complications are typically followed up for 6 weeks. Complex injuries are typically followed up for 3 months and above. Both injuries are followed for longer durations if deemed clinically necessary.

\section{Statistical Analysis}

The data were analyzed by using Stata v16. Continuous data are presented as median and interquartile range (IQR), while categorical data are presented as frequency and percentages.

Crude odds ratio (OR) was utilized for univariate analysis. Results are presented as OR and 95\% confidence intervals (CI). 
Due to the small number of cases with deep infection, multivariable logistic regression was deemed inappropriate to assess for factors affecting the risk of deep infection. In such cases, the maximum likelihood estimates used in the logistic regression model may be biased. Hence, only univariate modelling was utilized.

A $p$-value $<0.05$ was deemed to be statistically significant.

\section{Results}

There were 232 patients included in our study. The median age of cases was 33 years (range $=26-45$ ); $91 \%$ (211 patients) were males. Of the cases, $92 \%$ (214 patients) were performed under local anesthesia while the remaining $8 \%$ were performed under general or regional anesthesia.

Summary of demographic data, open fracture, timing to surgery, and antibiotic usage of the study population is shown in - Table 1.

Surgery was performed to the following regions: $71 \%$ (164 patients) to a single finger; $18 \%$ (41 patients) to multiple fingers; $8 \%$ (19 patients) to the hand; $2 \%$ (6 patients) to the wrist; and $1 \%$ ( 2 patients) to multiple regions.

Surgeries involving open fractures were evaluated. In total, 34\% (78 patients) of the cases involved open fractures, and the remaining $66 \%$ (154 patients) of cases involved only soft tissue injuries.

The breakdown of the types of surgeries is illustrated in -Fig. 1. Majority of cases involved only soft tissue debridement, while other more common cases consisted of soft tissue debridement, tendon repair, surgical bone fixation, terminalization, and skin grafting.
The median time to surgery was 45.9 hours (IQR: 42.4 ). In total, $99.1 \%$ (230) of our patients underwent surgery after 6 hours, while $73.7 \%$ (171) of patients after 24 hours. This is illustrated in - Fig. 2.

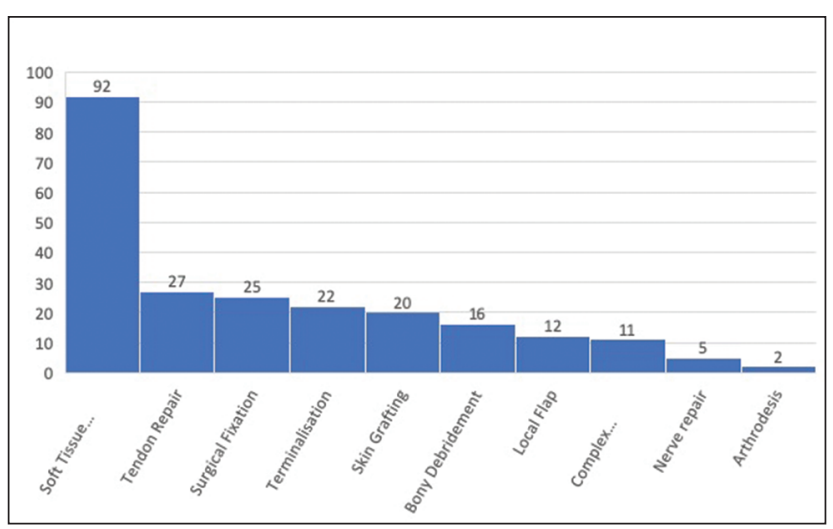

Fig. 1 Breakdown of the types of surgeries performed.

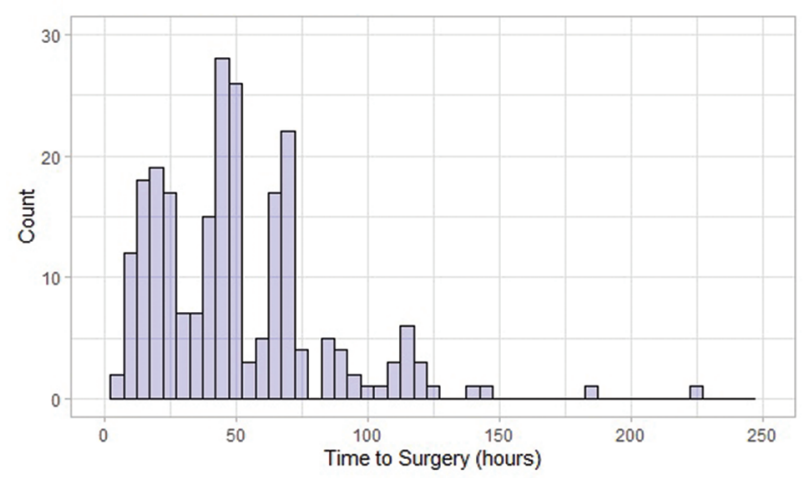

Fig. 2 Time to surgery (hours) in the patient population.

Table 1 Summary of demographic data, open fracture, timing to surgery, and antibiotic usage of the study population

\begin{tabular}{|c|c|c|c|c|c|}
\hline Characteristics & $\begin{array}{l}\text { Total study } \\
\text { population }(n)\end{array}$ & $\begin{array}{l}\text { Total infection } \\
\text { population }(n)\end{array}$ & Percentage (\%) & Crude OR $(95 \% \mathrm{Cl})$ & $p$-Value \\
\hline Population & 232 & 3 & 1.29 & & \\
\hline \multicolumn{6}{|l|}{ Gender } \\
\hline Male & 211 & 2 & 0.95 & $0.19(0.02-4.22)$ & \multirow[t]{2}{*}{0.185} \\
\hline Female & 21 & 1 & 4.76 & Ref. & \\
\hline \multicolumn{6}{|l|}{ Age } \\
\hline Median (IQR) & $33(19)$ & $46(11)$ & & $1.01(0.93-1.08)$ & 0.702 \\
\hline \multicolumn{6}{|l|}{ Open fractures } \\
\hline Yes & 78 & 2 & 2.56 & $4.03(0.38-87.45)$ & \multirow[t]{2}{*}{0.258} \\
\hline No & 154 & 1 & 0.65 & Ref. & \\
\hline \multicolumn{6}{|l|}{ Antibiotic usage } \\
\hline \multicolumn{6}{|l|}{ Intravenous in ED } \\
\hline Yes & 93 & 1 & 1.08 & $0.745(0.03-7.88)$ & \multirow[t]{2}{*}{0.811} \\
\hline No & 139 & 2 & 1.44 & Ref. & \\
\hline \multicolumn{6}{|l|}{ Postoperatively } \\
\hline Yes & 225 & 3 & 1.18 & NA & \multirow[t]{2}{*}{0.995} \\
\hline No & 7 & 0 & 0 & Ref. & \\
\hline
\end{tabular}

Abbreviations: ED, emergency department; $\mathrm{Cl}$, confidence interval; IQR, interquartile range; NA, not applicable; OR, odds ratio. 
The rate of deep-seated infection was 1.3\% (three patients) among all injuries and 2.6\% among all open hand fractures. These three cases who had postoperative infection are summarized in - Table 2 . No patients treated within 6 hours sustained postoperative infection.

The median time to surgery in the noninfected group was 46 hours (IQR: 42.7 ), while the median time to surgery in the infected group was 19.4 hours (IQR: 2.6 ). The results are illustrated in - Table 3 . Time to surgery was not associated with postoperative infection (OR: $0.95,95 \% \mathrm{CI}: 0.87-1.01, p=0.17$ ).

All patients were prescribed with oral antibiotics from ED except for $5.2 \%(n=12)$. Intravenous antibiotics was given in the ED to 93 patients (40\%). Out of these patients, one patient (1.1\%) sustained an infection postoperatively (OR: $0.74,95 \%$ CI: $0.03-7.88, p=0.81$ ). Of the patients given antibiotics, cefazolin was the most commonly used antibiotic. If patients were given multiple antibiotics, this was due to the addition of gentamicin in view of the open hand injuries sustained. For patients with cephalosporin allergies, an alternative antibiotic was given.

Although oral antibiotics were given routinely postoperatively, $3 \%$ of patients were not prescribed any antibiotics postoperatively. Of these, $2.6 \%(n=6)$ did not receive any antibiotics pre- and postoperatively. None of these six patients developed deep-seated postoperative infections $(p=0.99)$.

Using crude OR to examine factors affecting the risk of postoperative infection, none of the factors of age (OR: 1.01, $95 \%$ CI: $0.93-1.08, p=0.702$ ), time to surgery (OR: $0.95,95 \%$ CI: $0.87-1.01, p=0.174)$, antibiotic use preoperatively (OR:
0.74, 95\% CI: $0.03-7.88, p=0.811)$ antibiotic use postoperatively (OR: not applicable, $p=0.995$ ), nor open fractures (OR: $4.03,95 \% \mathrm{CI}: 0.38-87.45, p=0.258$ ) were statistically significant to affect the risk of postoperative of infection in our study.

\section{Discussion}

Based the current literature, infection rates of open hand injuries are up to $14 \% \cdot{ }^{13,14,18}$ Comparatively, our study had an infection rate of $1.3 \%$, where the majority of our cases $(85.3 \%)$ had surgery performed within 72 hours of ED presentation. Infection was also not associated with time to delay to surgery. This suggests that despite delayed surgical treatment, there were no increased rates of infection when compared with the rates of infection of open hand injuries in the literature. ${ }^{13,14,18}$

Various reasons for a delay in surgical treatment of open hand injuries have been identified. There could be limited operating capacity in smaller centers; multiple more urgent and life-threatening cases in high-volume centers; and large geographical distance to the nearest hand surgery center or difficult access to next available surgical center. ${ }^{14}$

We found that delayed time to surgery was not associated with postoperative infection. This corroborated with three other studies which suggest that time to surgery is not the main predictive factor in infection rates. Angly et al found that delayed surgical treatment (6-24 hours) did not increase infection or revision rates in open nondevascularized hand injuries, ${ }^{13}$ while Juon et al found that delayed

Table 2 Three cases for postoperative deep seated infection that required surgical debridement with positive postoperative cultures

\begin{tabular}{|c|c|c|c|c|c|c|c|}
\hline S no. & Diagnosis & $\begin{array}{l}\text { Operative } \\
\text { description }\end{array}$ & $\begin{array}{l}\text { Time to } \\
\text { surgery (h) }\end{array}$ & $\begin{array}{l}\text { IV } \\
\text { antibiotics } \\
\text { in ED }\end{array}$ & $\begin{array}{l}\text { Abx on discharge } \\
\text { from ED }\end{array}$ & Cultures & Outcome \\
\hline 1 & $\begin{array}{l}\text { Open bony mallet } \\
\text { of finger }\end{array}$ & Surgical fixation & 47.3 & Nil & $\begin{array}{l}\text { Amoxicillin/clavulanic } \\
\text { acid }\end{array}$ & $\begin{array}{l}\text { MSSA; Enterobacter } \\
\text { cloacae; Proteus } \\
\text { vulgaris }\end{array}$ & Infection resolved \\
\hline 2 & $\begin{array}{l}\text { Index finger nail } \\
\text { bed laceration }\end{array}$ & $\begin{array}{l}\text { Soft tissue } \\
\text { debridement }\end{array}$ & 9.2 & Nil & Clindamycin & $\begin{array}{l}\text { MSSA; Streptococcus } \\
\text { agalactiae }\end{array}$ & Infection resolved \\
\hline 3 & $\begin{array}{l}\text { Open proximal } \\
\text { phalanx fracture } \\
\text { with cut RDN }\end{array}$ & $\begin{array}{l}\text { Surgical fixation of } \\
\text { proximal phalanx } \\
\text { fracture and RDN } \\
\text { nerve graft }\end{array}$ & 19.4 & Cefazolin & $\begin{array}{l}\text { Amoxicillin/clavulanic } \\
\text { acid }\end{array}$ & Citrobacter Koseri & Ray amputation \\
\hline
\end{tabular}

Abbreviations: ED, emergency department; IV, intravenous; MSSA, methicillin-susceptible Staphylococcus aureus; RDN, radial digital nerve. Note: Operative details, antibiotics details, and outcomes are summarized in this table.

Table 3 Timing to surgery for the study population divided into those who sustained postoperative infection versus those who did not

\begin{tabular}{|l|l|l|l|l|l|}
\hline & Study population & $\begin{array}{l}\text { Noninfected } \\
\text { group }\end{array}$ & Infected group & Crude OR (95\% CI) & $p$-Value \\
\hline Number of patients & 232 & 229 & 3 & & \\
\hline Median age (IQR) & $33(19)$ & $33(18)$ & $46(11)$ & $1.01(0.93-1.08)$ & 0.70 \\
\hline $\begin{array}{l}\text { Time to surgery (h), } \\
\text { median (IQR) }\end{array}$ & $45.9(42.4)$ & $46.0(42.7)$ & $19.4(2.6)$ & $0.95(0.87-1.01)$ & 0.17 \\
\hline
\end{tabular}

Abbreviations: ED, emergency department; Cl, confidence interval; IQR, interquartile range; NA, not applicable; OR, odds ratio. 
surgical treatment (6-24 hours) of open hand injuries did not impact patients' outcome in terms of infections, complications, pain, and function. ${ }^{14}$ Finally, Davies et al reported that delaying surgery for open hand injuries by 4 days did not appear to increase the risk of surgical site infection. Skin loss, however, increased the risk of infection. ${ }^{17}$ Although Pavan et al found evidence to suggest a double peak for infection risk at the 6- and 24-hour mark, though this was not statistically significant when time to surgery was analyzed as a continuous variable. ${ }^{19}$

Historically, there has been a 6-hour rule to surgical debridement for all open fractures. ${ }^{7,15}$ This concept had worldwide acceptance but has been recently challenged in view of the paucity of evidence.

Due to its increased blood supply, open hand fractures were thought to be less susceptible to infection as compared with other open fractures. ${ }^{20,21}$ Many studies have shown that a delay in surgical debridement within 24 hours of surgical treatment did not have worse outcomes. ${ }^{13,14,16,22}$ In our study, in open hand fracture cases, rate of infection was not associated with time to delay in surgery.

It is important to note that the historical 6-hour rule of surgical treatment was established prior to the antibiotic era. ${ }^{15}$ The availability of antibiotic therapy has revolutionized

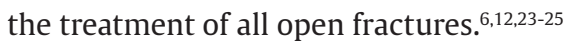

In open hand fractures, there was a correlation between administration of antibiotics and a reduction in infection rates. ${ }^{20,26}$ Patzakis and Wilkins found the administration of broad-spectrum antibiotics to be the most important factor in reducing infection, where the delay of debridement beyond 12 hours did not affect infection rates. Early administration of antibiotics was identified as another key factor. ${ }^{12}$ Similarly, Ketonis et al and Warrender et al found a correlation between administration of antibiotics and infection, where the timing of debridement did not affect infection rates for open hand fractures..$^{20,26} \mathrm{Ng}$ et al also found that there was a significant difference in infection rates among those who did not receive as compared with those that received IV antibiotics, despite the mean time to surgery being 82 hours in their review. ${ }^{22}$

In contrast, our study found that there was no association between administration of antibiotics (pre- and postoperatively) and infection rates. It is possible that our study had small numbers of positive cases to find a significant correlation between administration of antibiotics with infection rates. Yet, other factors apart from antibiotic use and time to surgery could contribute to infection rates. For example, skin loss, ${ }^{17}$ amount of wound irrigation fluid used in the $\mathrm{ED}^{27}$ degree of contamination, ${ }^{21,28}$ and age ${ }^{22}$ could have played a role in infection rates, although we found that age was also not associated with infection rates.

Our system of managing open hand injuries in the ambulatory, semi-emergent setting has shown numerous benefits. From the patient's perspective, it reduced waiting time for admission and prolonged inpatient stay while awaiting for OT availability. Overall treatment cost was also reduced by removing costs of inpatient expenses (an example can be seen in - Table 4). Procedures performed during office hours allowed for an experienced surgical team (surgeon, nursing,
Table 4 Overall treatment cost in a patient requiring debridement and nerve repair performed as an ambulatory case as compared with inpatient admission ${ }^{a}$

\begin{tabular}{|l|l|l|}
\hline & $\begin{array}{l}\text { Nerve repair } \\
\text { (day case) } \\
\text { Singapore dollars } \\
\text { (S\$) }\end{array}$ & $\begin{array}{l}\text { Nerve repair } \\
\text { (admission) } \\
\text { Singapore dollars } \\
\text { (S\$) }\end{array}$ \\
\hline $\begin{array}{l}\text { Day surgery } \\
\text { facility charge }\end{array}$ & 86 & 86 \\
\hline Consumables & $1,209.23$ & $1,209.23$ \\
\hline Surgical procedure & $3,920.25$ & $3,920.25$ \\
\hline Microscope use & 192.60 & 192.60 \\
\hline Inpatient stay & Nil & $500(2 \mathrm{~d})$ \\
\hline $\begin{array}{l}\text { Hand occupational } \\
\text { therapist visits }\end{array}$ & $320(4$ visits) & $320(4$ visits) \\
\hline Hand doctor visits & $408(4$ visits) & $408(4$ visits) \\
\hline Total costs & $6,136.08$ & $6,636.08$ \\
\hline
\end{tabular}

aThis is under the assumption that the patient qualifies for subsidized healthcare. The charges above are at subsidized rates.

and OT staff) to be present. Screening of cases preoperatively could be achieved, allowing for the preparation of adjunctive equipment or implants (microscope, fixation devices, nerve, or tendon grafts). Our system has achieved benefits similar to a daytime semi-elective orthopedic trauma surgery list, where this list allowed for increased consultant supervision in the management of trauma patients, increasing the quality of patient care. ${ }^{29-33}$

In our country, this is the first study to examine the association of infection rates in open hand injuries with relation to the timing to surgery. We recommend that open hand injuries that do not require critical revascularization can be considered for semi-emergency management in the ambulatory setting. Surgery may be delayed to the next available semi-emergent hand list with no significant increase in infection rates postoperatively. This may be an acceptable means of managing such cases, allowing a specialized team of health care professionals including allied and an auxiliary healthcare team familiar with hand surgery to deliver care while allowing senior staff supervision for all cases.

\section{Limitations}

This is a retrospective study. The low number of positive cases could have affected the statistical power of observations made. This study was not a controlled study and comparison of infection rates were based upon those published in available literature.

As we are presenting our data in our ambulatory surgery setting, our data may not represent all open hand injuries presented to our institution, though the proportion of excluded cases are likely to be small.

The only examined outcome was rates of deep infection. Other outcome measures such as functional outcomes were not evaluated in this study. 
Despite these limitations, the results were encouraging and showed no increased infection rates in our patients. In view of the low rates of infection, a multicentered study may be helpful to boost the power of subsequent studies.

A future controlled study with a prospective nature looking at both superficial and deep infection rates may shed further light into this paradigm shift in managing open hand injuries. Degree of contamination, skin loss, and age are other factors that will be useful to look at. Other outcome parameters of functional outcome, pain, and days off work can be evaluated in subsequent studies for an overall assessment.

\section{Conclusion}

A delay to time of surgical treatment of open hand injuries was not associated with increased rates of deep-seated infection in this retrospective single-center study as compared with available literature. Treatment of open injuries of the hand in the ambulatory setting, as a semi-emergent day surgery case, may be an acceptable means of managing open hand injuries. It affords the utilization of a specialized team of health care professionals familiar with hand surgery to deliver care while at the same time allowing for senior staff supervision.

\section{Funding \\ None.}

\section{Conflict of Interest}

None declared.

\section{Acknowledgments}

The authors would like to acknowledge Chalani Udhyami Ubeynarayana for her kind help with the statistics for this paper.

\section{References}

1 Niska R, Bhuiya F, Xu J. National Hospital Ambulatory Medical care survey: 2007 emergency department summary. Natl Health Stat Rep 2010; (26):1-31

2 de Putter CE, Selles RW, Polinder S, Panneman MJ, Hovius SER, van Beeck EF. Economic impact of hand and wrist injuries: health-care costs and productivity costs in a population-based study. J Bone Joint Surg Am 2012;94(9):e56

3 Maroukis BL, Chung KC, MacEachern M, Mahmoudi E. Hand trauma care in the united states: a literature review. Plast Reconstr Surg 2016;137(1):100e-111e

4 Larsen CF, Mulder S, Johansen AMT, Stam C. The epidemiology of hand injuries in The Netherlands and Denmark. Eur J Epidemiol 2004;19(4):323-327

5 Rosberg HE, Dahlin LB. Epidemiology of hand injuries in a middle-sized city in southern Sweden: a retrospective comparison of 1989 and 1997. Scand J Plast Reconstr Surg Hand Surg 2004;38(6):347-355

6 Gosselin RA, Roberts I, Gillespie WJ. Antibiotics for preventing infection in open limb fractures. Cochrane Database Syst Rev 2004; (1):CD003764

7 Gustilo RB, Anderson JT. Prevention of infection in the treatment of one thousand and twenty-five open fractures of long bones: retrospective and prospective analyses. J Bone Joint Surg Am 1976;58(4):453-458
8 Harley BJ, Beaupre LA, Jones CA, Dulai SK, Weber DW. The effect of time to definitive treatment on the rate of nonunion and infection in open fractures. J Orthop Trauma 2002;16(7):484-490

9 Nanchahal J, British Association of Plastic R and AS. Standards for the Management of Open Fractures of the Lower Limb Royal Society of Medicine Press Ltd; 2009

10 Schenker ML, Yannascoli S, Baldwin KD, Ahn J, Mehta S. Does timing to operative debridement affect infectious complications in open long-bone fractures? A systematic review. J Bone Joint Surg Am 2012;94(12):1057-1064

11 Spencer J, Smith A, Woods D. The effect of time delay on infection in open long-bone fractures: a 5-year prospective audit from a district general hospital. Ann R Coll Surg Engl 2004;86(2):108-112

12 Patzakis MJ, Wilkins J. Factors influencing infection rate in open fracture wounds. Clin Orthop Relat Res 1989; (243):36-40

13 Angly B, Constantinescu MA, Kreutziger J, Juon BH, Vögelin E. Early versus delayed surgical treatment in open hand injuries: a paradigm revisited. World J Surg 2012;36(4):826-829

14 Juon BH, Iseli M, Kreutziger J, Constantinescu MA, Vögelin E. Treatment of open hand injuries: does timing of surgery matter? A single-centre prospective analysis. J Plast Surg Hand Surg 2014;48(5):330-333

15 Friedrich PL. Die aseptische Versorgung frischer Wunden. Available at: https://www.scirp.org/(S(i43dyn45teexjx455qlt $3 \mathrm{~d} 2 \mathrm{q})$ )/reference/ReferencesPapers.aspx?ReferenceID= 1819554. Accessed 1898

16 McLain RF, Steyers C, Stoddard M. Infections in open fractures of the hand. J Hand Surg Am 1991;16(1):108-112

17 Davies J, Roberts T, Limb R, Mather D, Thornton D, Wade RG. Time to surgery for open hand injuries and the risk of surgical site infection: a prospective multicentre cohort study. J Hand Surg Eur Vol 2020;45(6):622-628

18 Nylén S, Carlsson B. Time factor, infection frequency and quantitative microbiology in hand injuries: a prospective study. Scand J Plast Reconstr Surg 1980;14(2):185-189

19 Pavan F, Albarki HS, Vu J, Keating C, Leong JC. Does delay to theater lead to increased infection rates in hand trauma? A retrospective cohort study. Plast Reconstr Surg Glob Open 2018;6(11):e2025

20 Warrender WJ, Lucasti CJ, Chapman TR, Ilyas AM. Antibiotic management and operative debridement in open fractures of the hand and upper extremity: a systematic review. Hand Clin 2018;34(1):9-16

21 Tulipan JE, Ilyas AM. Open fractures of the hand: review of pathogenesis and introduction of a new classification system. Hand Clin 2018;34(1):1-7

$22 \mathrm{Ng}$ T, Unadkat J, Bilonick RA, Wollstein R. The importance of early operative treatment in open fractures of the fingers. Ann Plast Surg 2014;72(4):408-410

23 Patzakis MJ, Harvey JP Jr, Ivler D. The role of antibiotics in the management of open fractures. J Bone Joint Surg Am 1974;56(3):532-541

24 Hauser CJ, Adams CA Jr, Eachempati SR; Council of the Surgical Infection Society. Surgical Infection Society guideline: prophylactic antibiotic use in open fractures: an evidence-based guideline. Surg Infect (Larchmt) 2006;7(4):379-405

25 Jaeger M, Maier D, Kern WV, Südkamp NP. Antibiotics in trauma and orthopedic surgery: a primer of evidence-based recommendations. Injury 2006;37(Suppl 2) :S74-S80

26 Ketonis C, Dwyer J, Ilyas AM. Timing of debridement and infection rates in open fractures of the hand: a systematic review. Hand (N Y) 2017;12(2):119-126

27 Basat NB, Allon R, Nagmi A, Wollstein R. Treatment of open fractures of the hand in the emergency department. Eur J Orthop Surg Traumatol 2017;27(3):415-419 
28 Glueck DA, Charoglu CP, Lawton JN. Factors associated with infection following open distal radius fractures. Hand (N Y) 2009;4(3):330-334

29 Operating at night. Lancet 1991;338(8772):921

30 Jennings AG, Saeed K, Dolan S, Wise DI. Impact of the introduction of a daily trauma list on out-of-hours operating. Ann R Coll Surg Engl 1999;81(1):65-68

31 Gulamhussein MA, Chaudhry S, Noor S, Chaudhry T, Guha A, Knebel R. Safety in out-of-hours operating in trauma and orthopaedics at a district general hospital. Ann R Coll Surg Engl 2017;99(5):347-350

32 Chacko AT, Ramirez MA, Ramappa AJ, Richardson LC, Appleton PT, Rodriguez EK. Does late night hip surgery affect outcome? J Trauma 2011;71(2):447-453

33 Yeatman M, Cameron-Smith A, Moore JM. Nocturnal orthopaedic operating: can we let sleeping orthopaedic surgeons lie? Ann R Coll Surg Engl 1994;76(2):90-94 